\title{
Validation of Fuel-Coolant Interaction Model for Severe Accident Simulations
}

\author{
Vladimir Melikhov, ${ }^{1}$ Oleg Melikhov, ${ }^{2}$ Sergey Yakush, ${ }^{3}$ and Nikita Rtishchev ${ }^{2}$ \\ ${ }^{1}$ Thermo-Hydraulics Division, Electrogorsk Research and Engineering Center for Safety of Nuclear Power Plants, \\ Saint Constantine Street 6, Moscow Region, Electrogorsk 142530, Russia \\ ${ }^{2}$ NPP Department, Moscow Power Engineering Institute, Krasnokazarmennaya Street 14, Moscow 111250, Russia \\ ${ }^{3}$ Thermogasdynamics and Combustion Laboratory, A. Yu. Ishlinskiy Institute for Problems in Mechanics, \\ Russian Academy of Sciences, 101/1 Vernadskogo Avenue, Moscow 119526, Russia
}

Correspondence should be addressed to Vladimir Melikhov, vladimir.melikhov@erec.ru

Received 31 May 2011; Revised 12 July 2011; Accepted 26 July 2011

Academic Editor: Giorgio Galassi

Copyright ( 2011 Vladimir Melikhov et al. This is an open access article distributed under the Creative Commons Attribution License, which permits unrestricted use, distribution, and reproduction in any medium, provided the original work is properly cited.

A specialized module VAPEX-M has been developed and implemented as a part of an integral code, SOCRAT, to enable the modeling of fuel-coolant interactions (FCIs) during severe accidents. The mathematical model and correlations for the main physical processes are described. Results of computational analysis of three experimental series reported in the literature are presented. The calculations were carried out by the combined SOCRAT/VAPEX code and were aimed at validation of the predictive capabilities of the code. The experiments chosen cover a wide range of physical parameters, which enables different aspects of the code to be verified, that is, drag correlations (MAGICO-2000), evaporation rate (QUEOS), fuel fragmentation, and interaction with the coolant in all complexity (FARO). Generally, reasonable agreement between the measured data and calculated results was obtained, which allows one to use the combined SOCRAT/VAPEX code for severe accidents analysis.

\section{Introduction}

During a severe reactor accident, molten core material (corium) can relocate in the lower plenum of the reactor pressure vessel (RPV) or, after failure of the RPV, it can be released into the containment cavity. Taking into account the presence of water in the degraded/molten core or in the reactor cavity, this could lead to one or more energetic fuelcoolant interactions (FCIs) [1-3].

FCI is usually divided into the premixing and explosion phases, characterized by different time scales for the dominant processes [4]. During the premixing phase, the core melt flows into the water in the form of jets and is progressively transformed into droplets (of sizes in the range from few millimetres to centimetres) which are dispersed into the two-phase coolant. The melt vaporises part of the coolant during this contact and stable vapour film boiling develops around the droplets. Due to relatively slow heat transfer between the melt drops and water, such a mixture can be considered as stable (no liquid-liquid contact). All these major processes take place at time scales from few tenths of a second to several seconds.

The explosion phase can be initiated by the destabilisation of the vapour film around the melt drops, leading to rapid heat transfer, local pressure rises, and fine fragmentation. This can generate shock waves propagating at supersonic speed through the multiphase mixture. Fine fragmentation (to sizes of the order of some ten microns) of the melt in the wave results in the increased heat transfer, thus, supporting its escalation. The shock waves can damage the RPV and containment, posing a significant risk of release of fission products into the environment. The time-scale characteristic of the explosion phase is of the order of few milliseconds.

FCI has been a long-standing matter of concern in nuclear reactor safety $[1-10]$. During the recent years, the research focus has shifted from the early containment failure as a consequence of an in-vessel steam explosion (the 
famous $\alpha$-mode failure) to possible consequences of steam explosions, primarily ex-vessel but also in-vessel, though in a context different from the $\alpha$-mode failure. Evaluation of possible hazards is largely based on the experimental information. Also, for estimating the possible consequences of such cases, multifluid thermohydraulic codes are developed and validated on experimental data in several countries [5].

In Russia, a stand-alone code VAPEX-P intended for the two-dimensional simulation of fuel-coolant interactions has been under development for a number of years at EREC [6-9]. On the other hand, an integral code SOCRAT has been developed for the analysis of in-vessel stage of severe accidents in pressurized water reactors. SOCRAT includes several principal modules which describe core degradation and melt relocation taking into account the coupled physical and chemical processes (SVECHA), thermohydraulics (RATEG), and behavior of core materials relocated into the reactor lower plenum (HEFEST) $[10,11]$.

Recently, a module VAPEX-M, based on the standalone code VAPEX-P and describing the interaction of molten corium with coolant, has been added to the abovementioned principal modules of SOCRAT to enable detailed simulations of FCI processes during severe accidents. In the combined code, the module VAPEX-M uses Lagrangian approach for the simulation of the molten corium, it describes the processes of heat and mass transfer (heat fluxes from the high-temperature melt into the liquid and vapor phases, hydrogen production rate due to the oxidation of zirconium and steel) and provides relevant data for the thermohydraulic module, which is a part of SOKRAT.

In this paper, results of validation studies carried out by the combined SOKRAT/VAPEX code are presented. Three experimental series reported in the literature were chosen for the validation calculations: MAGICO [12, 13], QUEOS $[14,15]$, and FARO [16-18]. These experiments allow different aspects of fuel-coolant interaction to be verified: drag correlations (MAGICO), evaporation rate (QUEOS), fuel fragmentation, and interaction with the coolant in all complexity (FARO).

It should be pointed out that SOKRAT, being an integral code, simulates the whole reactor vessel and circulation loops, and, due to computational requirements, it rather coarse mesh cells are used. Therefore, it was decided during the validation studies to check the capabilities of VAPEX module in the conditions which can be encountered in real-case calculations. For this purpose, the grids, on which SOCRAT solves the thermohydraulic equations, were chosen to be one dimensional, with the cells arranged in the vertical direction. Comparisons with two-dimensional VAPEX-P calculations are also presented.

\section{Mathematical Model}

The thermohydraulics model in SOCRAT code uses the multifluid approach (i.e., coupled equations for phase continuity, momentum, and energy of each phase) and is described elsewhere $[10,11]$. Here, the main features of the dispersed phase model implemented in VAPEX-M module are described.
To describe the dispersed phase (melt or particles), the Lagrangian approach is used. The melt is considered as a large number of particle groups (macroparticles), and for each group the equations of motion are solved together with the equations for heat and mass transfer processes. The volume fractions of liquid, vapour, and dispersed particles satisfy the compatibility condition $\alpha_{l}+\alpha_{v}+\alpha_{d}=1$. The system of governing equations for $k$ th macroparticle is

$$
\begin{gathered}
\frac{d \mathbf{r}^{k}}{d t}=\mathbf{U}_{d}^{k}, \\
\rho_{d} \frac{d \mathbf{U}_{d}^{k}}{d t}=\mathbf{F}_{d l}^{k}+\mathbf{F}_{d v}^{k}+\left(\rho_{d}-\rho_{a}\right) \mathbf{g}, \\
\rho_{d} \frac{d H_{d}^{k}}{d t}=-\dot{q}_{d l}^{k}-q_{d v}^{k}+\dot{q}_{N}^{k}+\dot{q}_{\mathrm{ox}}^{k}
\end{gathered}
$$

(all forces and heat transfer rates are per unit volume of melt of $k$ th macroparticle). The temperature dependence of specific enthalpy $h_{d}=h_{d}\left(T_{d}\right)$ takes into account the phase transition effects and is prescribed as a piecewise-linear function.

The drag forces and heat transfer coefficients in (1) are described by correlations [12, 13, 19] taking into account different flow regimes which can exist in the two-phase flow

$$
\begin{gathered}
\mathbf{F}_{d i}=c_{d i}\left|\mathbf{U}_{d}-\mathbf{U}_{i}\right|\left(\mathbf{U}_{i}-\mathbf{U}_{d}\right), \quad c_{d i}=\frac{3}{4} \varphi_{d i} \rho_{i} \frac{C_{D i}}{D_{p}}, \\
C_{D i}=C_{D i}^{*}\left\{\frac{1+17.76 f\left(\alpha_{d}\right)^{6 / 7}}{18.67 f\left(\alpha_{d}\right)}\right\}^{2}, \\
f\left(\alpha_{d}\right)=\sqrt{1-\alpha_{d}}\left(1-\frac{\alpha_{d}}{0.62}\right)^{1.55}, \\
C_{D i}^{*}=\frac{24}{\operatorname{Re}_{d i}}+\frac{4}{\sqrt{\operatorname{Re}_{d i}}}+0.4 \\
\operatorname{Re}_{d i}=\frac{D_{p}\left|\mathbf{U}_{d}-\mathbf{U}_{i}\right| \rho_{i}}{\mu_{i}} .
\end{gathered}
$$

The factor $\varphi_{d i}=\alpha_{i} /\left(\alpha_{l}+\alpha_{g}\right)$ in (2) takes into account the relative contact area of droplets with $i$ th phase $(i=l, g)[12$, $13,19]$. The drag laws $(2)-(6)$ are applied to macroparticles which represent both the melt jet entering the liquid, and the melt droplets which are formed due to its fragmentation. However, the physical conditions in which these two types of particles move are different. The jet (or a dense cloud of particles) generates quite powerful coflow in the coolant, so that the conditions for the leading particles are different from those for the trailing particles. For example, it was found in MAGICO-2000 experiments $[12,13]$ that a cloud of falling particles forms a "funnel" on the water surface, and the initial cylindrical particulate cloud transforms into an "inverted cup" shape. This effect is essentially non-one-dimensional, and special treatment is necessary to describe the particles in the quasi-one-dimensional framework of SOCRAT code. Therefore, appropriate corrections are necessary.

An approach which was found effective is the following. The drag laws (2)-(6) are applied only to the particles which are currently located at or near the leading front of the jet 
(or particulate cloud); for the trailing particles, the effective velocity of the continuous phase is modified:

$$
\widetilde{\mathbf{U}}_{i}=\mathbf{U}_{i}+\chi \mathbf{U}_{d}^{l},
$$

where $\mathbf{U}_{d}^{l}$ is the velocity of the leading particle, and $\chi$ is an empirical coefficient $(\chi=0$ corresponds to independent sedimentation of particles at small concentrations, while for $\chi=1$ the trailing particles are almost unaffected by drag, reaching the leader particles and becoming new leaders, as is the case for highly concentrated clouds or jets). The dependence of $\chi$ on the volume fraction of melt was established in the calculation of MAGICO-2000 experiments and will be discussed later.

Heat transfer between the melt droplets and two-phase mixture is described by correlations $[12,13]$ depending on void fraction $\phi$. For $\phi<0.7$, the droplets are assumed to be in film boiling regime with corresponding radiative and convective heat transfer coefficients $h_{r}$ and $h_{c l}$

$$
\dot{q}_{d l}=\frac{6}{D_{p}}\left(h_{r}+h_{c l}\right)\left(T_{d}-T_{l}\right) .
$$

The radiative heat transfer coefficient between the melt and liquid water is

$$
h_{r}=\sigma E_{d} \frac{T_{d}^{4}-T_{l}^{4}}{T_{d}-T_{l}}
$$

while the convective heat transfer coefficient is

$$
h_{c l}=2.98\left\{\frac{\rho_{g} \lambda_{g}\left[L+0.68 c_{p g}\left(T_{d}-T_{l}\right)\right]}{D_{p}\left(T_{d}-T_{l}\right)}\left|\mathbf{U}_{d}-\mathbf{U}_{l}\right|\right\}^{1 / 2} .
$$

In this regime, heat transfer from droplets to gas phase is not taken into account $\left(\dot{q}_{d g}=0\right)$.

For $\phi \geq 0.7$, the melt droplets are in gas with water drops. By radiation, the melt transfers heat to water, by convection to the surrounding gas

$$
\dot{q}_{d l}=\frac{6}{D_{p}} h_{r}\left(T_{d}-T_{l}\right), \quad \dot{q}_{d g}=\frac{6}{D_{p}} h_{c g}\left(T_{d}-T_{g}\right),
$$

where the radiative heat transfer coefficient is evaluated from (9) while the convective heat transfer coefficient is

$$
h_{c g}=\frac{\lambda_{g}}{D_{p}}\left(2+0.6 \operatorname{Re}_{g}^{1 / 2} \operatorname{Pr}_{g}^{1 / 3}\right) .
$$

Relations (8)-(12) provide the specific heat transfer rate from individual particles. The corresponding source terms in the thermohydraulic equations are obtained by summing up inputs from all particles in a computational cell and dividing it by the cell volume. For the film boiling regime, the radiative heat transfer rate is multiplied by the water absorptivity $E_{l}=$ 0.3 while the absorbing surface area that is of water droplets is obtained from the droplet diameter $D_{l}$ evaluated from the stability criterion $\rho_{g}^{2}\left|\mathbf{U}_{l}-\mathbf{U}_{g}\right| D_{l} / \sigma_{l g}=\mathrm{We}_{\mathrm{cr}}$, where $\mathrm{We}_{\mathrm{cr}}=12$ is the critical Weber number.
The fragmentation of coherent melt jet is described by the model presented in [20] and used in TEXAS-V code. The jet is modeled by a set of macroparticles each having its own diameter, velocity, and temperature. The particle diameter decreases with time according to equation

$$
\frac{d D_{p}}{d t}=-\left(0.1093-0.078\left(\frac{\rho_{a}}{\rho_{d}}\right)^{1 / 2}\right)\left(\frac{\rho_{a}}{\rho_{d}}\right)^{1 / 2} \mathrm{We}^{0.246} V_{r},
$$

where $V_{r}=\left|\mathbf{U}_{d}-\mathbf{U}_{a}\right|$ is the relative velocity of droplet with respect to mixture, $\mathrm{We}=\rho_{a}^{2} V_{r} D_{p} / \sigma_{d}$ is the Weber number. Fragmentation occurs not for all particles, but only for some $N_{L}$ leading particles (i.e., having the minimum vertical coordinates for a given melt jet). The particular value for $N_{L}$ was determined in the test calculations. In addition to coherent jet fragmentation, secondary fragmentation of melt drops is included in the model; the initial diameter of melt fragments was typically taken to be $5 \mathrm{~mm}$, after which droplets fragmented further if their Weber number exceeded critical value of 12 . Alternatively, the diameter of fragmented droplets can be specified ad hoc, provided that some experimental information is available. Note finally that the heat release rate $\dot{q}_{\mathrm{ox}}$ due to oxidation of zirconium is zero for the materials considered in this work. Validation of zirconium oxidation model is beyond the scope of current paper.

\section{Validation Results}

3.1. Validation Matrix. As a first step, the key physical and hydrodynamic processes and phenomena characteristic of nonexplosive corium water in the in-vessel conditions were identified (see Table 1). Evidently, FCI is a complex process involving several interconnected physical phenomena, and validation studied should include the calculation of separate physical phenomena, as well as integral calculations of the FCI process as a whole.

Representative test facilities, which were available for FCI investigations worldwide, were analyzed from the literature. Generally speaking, all test scenarios were similar; high-temperature material (molten or solid) was dropped into water pool. The main differences were in the mass, composition and temperature of the corium, depth of water pool and water temperature, and system pressure. Typical measurements available include the time histories of the system pressure, water and melt temperatures at different locations. The sizes of corium fragments were also measured when molten material was used. Sometimes, multiphase transients were recorded by video.

The results obtained on three test facilities MAGICO$2000[12,13]$, QUEOS $[14,15]$, and FARO [16-18] were selected for the validation of VAPEX-M module, see Table 2. The main aim of MAGICO and QUEOS tests was to study in detail the mixing of melt fragments with the water. Fixed-size metallic balls were used as simulators of fragmented melt to reduce the uncertainties connected with the interfacial area, which facilitates the code validation in terms of reproduction of separate physical effects. 


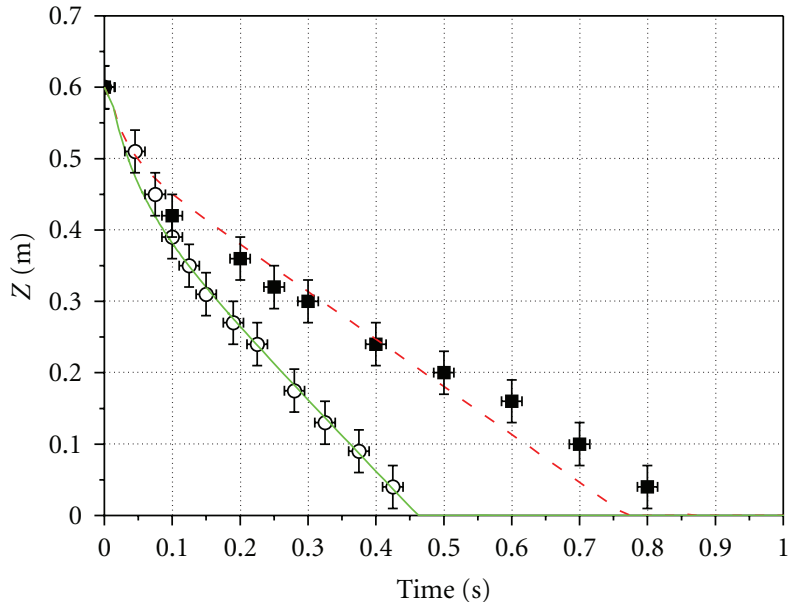

- $2.9 \mathrm{~mm}$ (experiment) - - $2.9 \mathrm{~mm}$ (VAPEX-M)

○ $6.3 \mathrm{~mm}$ (experiment) $6.3 \mathrm{~mm}$ (VAPEX-M)

(a)

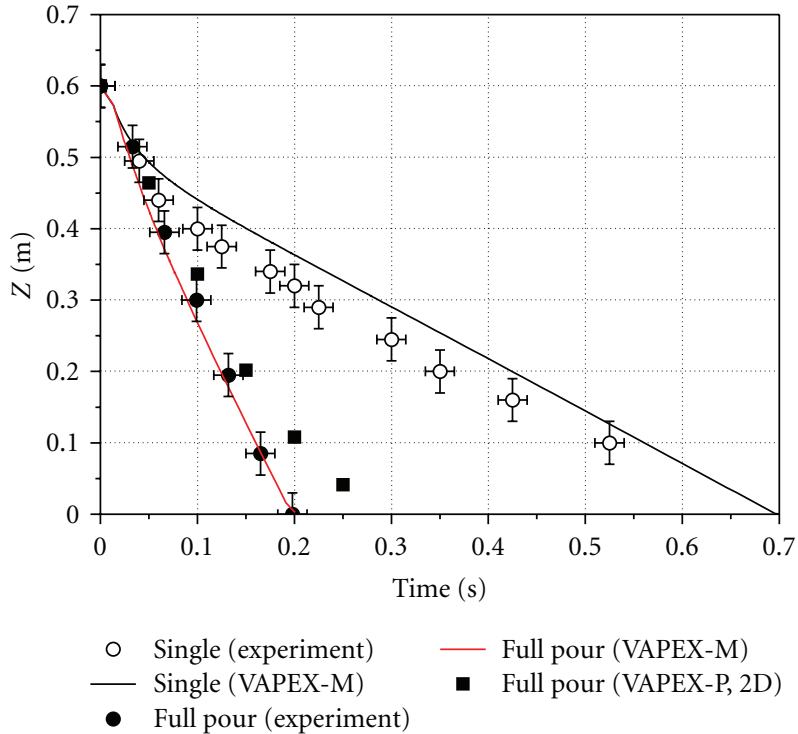

(b)

FIGURE 1: Sedimentation of cold particles: (a) single $\mathrm{ZrO}_{2}$ particles of different diameters; (b) $2.4 \mathrm{~mm}$ steel single particles and particulate clouds (experiment MF.AX [12, 13]).

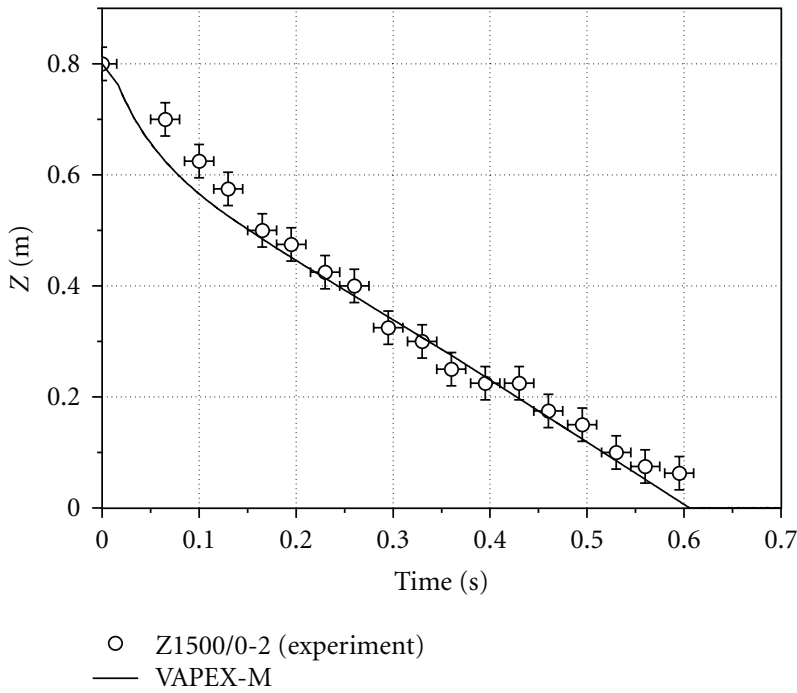

(a)

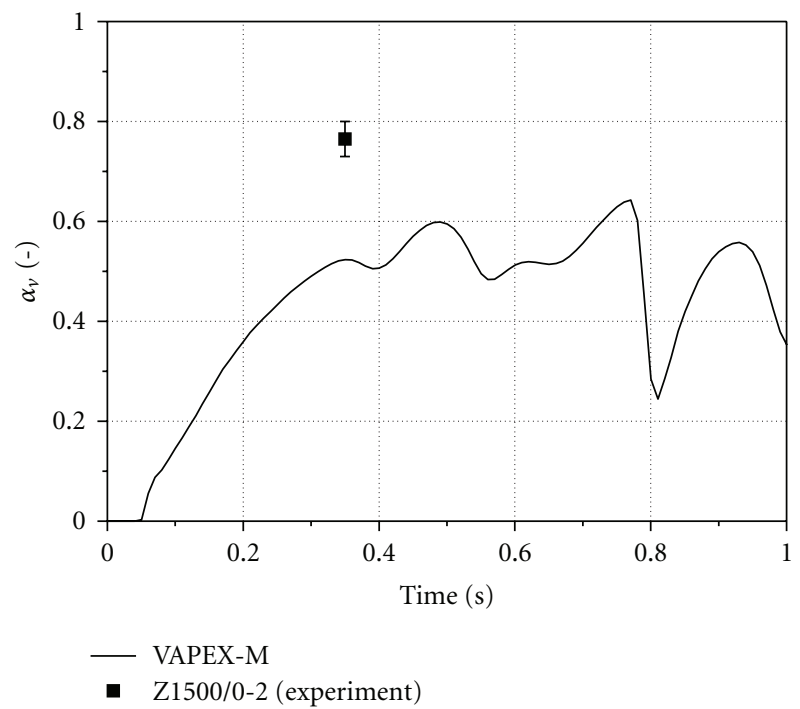

(b)

Figure 2: Plunging of a cloud of hot $2.9 \mathrm{~mm} \mathrm{ZrO}_{2}$ particles (experiment $\mathrm{Z1500/0-2} \mathrm{[12,} \mathrm{13]):} \mathrm{(a)} \mathrm{sedimentation} \mathrm{history;} \mathrm{(b)} \mathrm{void} \mathrm{fraction} \mathrm{at}$ $t=0.35 \mathrm{~s}$.

The interaction of large masses of the core melt $\left(\mathrm{UO}_{2}-\right.$ $\mathrm{ZrO}_{2}-\mathrm{Zr}$ ) with water under realistic severe accident conditions was the objective of the FARO tests. Although the melt mass in the FARO tests was two orders of magnitude smaller than the prototypic NPP case, it exceeds by an order of magnitude the masses involved in all other tests. The other parameters (water pool depth, pressure and temperature, gravity-driven melt injection mode) are prototypical for the NPP conditions.

3.2. Calculation of MAGICO-2000 Experiments. In the MAGICO-2000 experiments [12, 13], plunging of single particles and concentrated particulate clouds (cold and heated) into water pool was studied. The main parameter of interest in the experiments and calculations was the vertical coordinate of the leading edge of particulate cloud. The experimental position and time uncertainties are $\pm 3 \mathrm{~cm}$ and $\pm 0.015 \mathrm{~s}$, respectively.

Results of the calculations performed for the cold particles are plotted in Figure 1 together with the experimental data from $[12,13]$. In Figure 1(a), results obtained for single $\mathrm{ZrO}_{2}$ particles entering a $0.6 \mathrm{~m}$-deep water pool with the initial velocity $5 \mathrm{~m} / \mathrm{s}$ (particle diameters 2.9 and $6.3 \mathrm{~mm}$ ) are presented. One can see good agreement of calculated and 


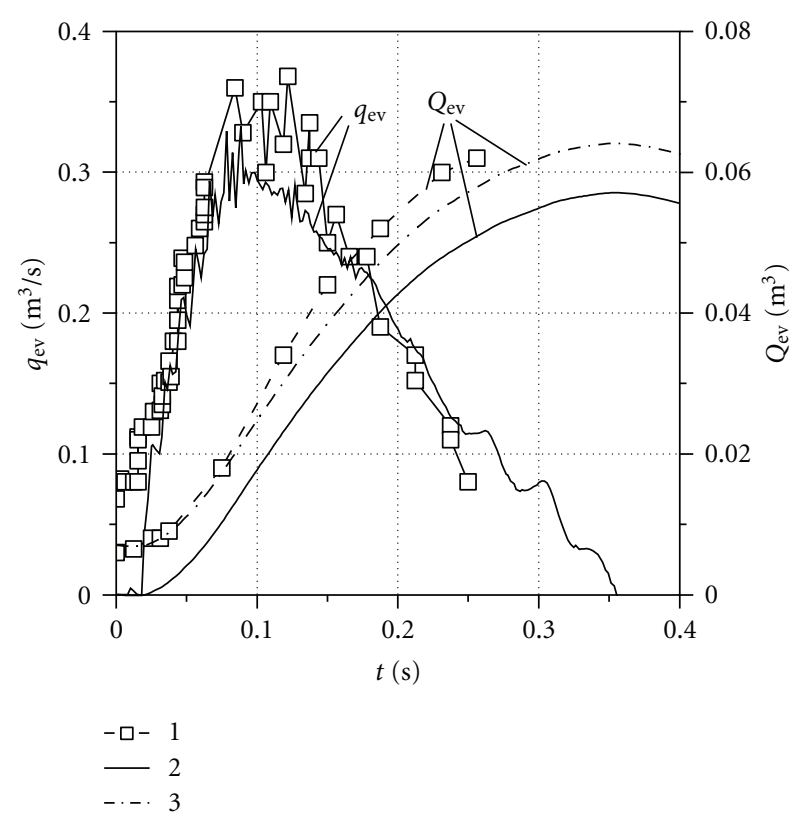

(a)

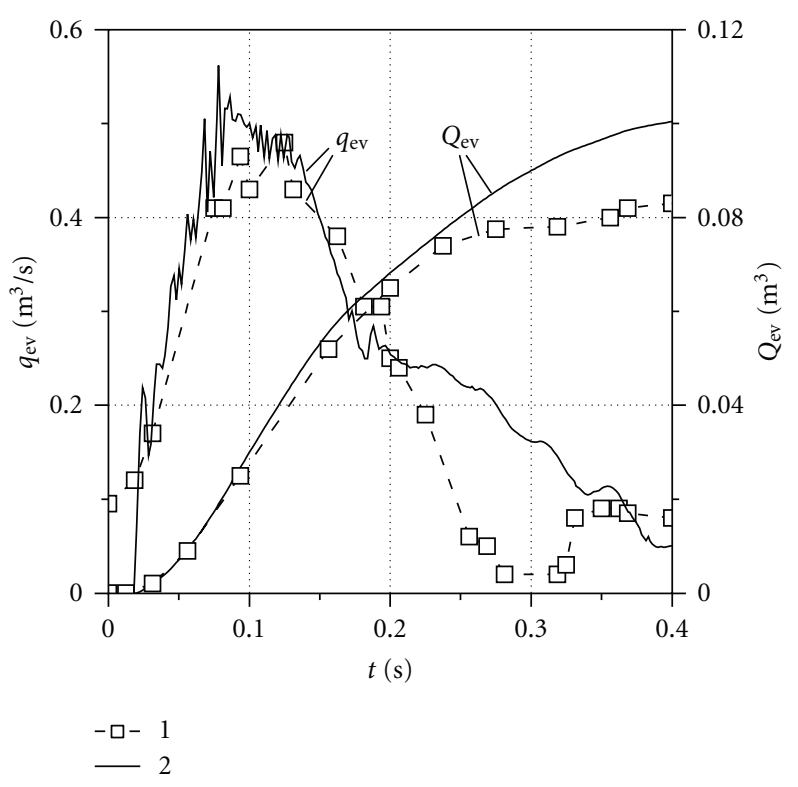

(b)

FIgURE 3: Time dependencies of the vapour flowrates $q_{\mathrm{ev}}$ and total vapour volume $Q_{\mathrm{ev}}$ in the QUEOS experiments Q10 (a) and Q11 (b): 1 -experiments, 2-VAPEX-M, 3-VAPEX-M (corr.).

TABLE 1: Description of FCI phenomena.

\begin{tabular}{|c|c|c|}
\hline No & Phenomena & Description \\
\hline (1) & Melt jet breakup & $\begin{array}{l}\text { The core melt flows into the water in the form of jets and is progressively } \\
\text { transformed into droplets (in a range from a few millimeters to } \\
\text { centimeters) which are dispersed into the two-phase coolant. The } \\
\text { interfacial melt-water area is determined by diameter and quantity of melt } \\
\text { droplets. }\end{array}$ \\
\hline (2) & Mixing of melt droplets with water & $\begin{array}{l}\text { Dynamics of this process influences on amount of the water involved in } \\
\text { FCI. }\end{array}$ \\
\hline (3) & Steam production & $\begin{array}{l}\text { Interaction of the high-temperature molten corium }(\sim 2500-3000 \mathrm{~K}) \text { with } \\
\text { water leads to the production of huge amount of steam. The steam is } \\
\text { injected in the containment and increases pressure. The amount of the } \\
\text { produced steam is determined by the heat transfer rate, which, in turn, is } \\
\text { dependent on the interfacial melt-water area, melt-water temperature } \\
\text { difference, and heat transfer mode (film boiling, convective heat transfer, } \\
\text { etc.). }\end{array}$ \\
\hline (4) & Hydrogen generation & $\begin{array}{l}\text { Corium can contain metallic components (zirconium, steel), its oxidation } \\
\text { leads to hydrogen generation. Also hydrogen generation was observed in } \\
\text { the FARO test with interaction of the water and uranium-zirconium oxides } \\
\text { mixture (without metallic). }\end{array}$ \\
\hline (5) & Corium quenching & $\begin{array}{l}\text { Due to interaction with cold water }(\sim 450-550 \mathrm{~K}) \text {, corium is quenched. The } \\
\text { dynamics of this process is determined by heat transfer rate between } \\
\text { corium and steam-water mixture. }\end{array}$ \\
\hline
\end{tabular}

measured particle coordinates, especially for the larger particle. The smaller particle initially moves in the experiments faster than in the calculation but then decelerates and reaches the same terminal velocity. Generally, the accuracy of the results obtained is comparable with that of the analytical solution from $[12,13]$.

In Figure 2, results obtained for the experiment MF.AX ( $2.4 \mathrm{~mm}$ steel particles, cloud mass $12.2 \mathrm{~kg}$, particle velocity
$5 \mathrm{~m} / \mathrm{s}$, water depth $0.6 \mathrm{~m}$, initial volume fraction of particles $13.3 \%$, cloud length $37 \mathrm{~cm}$, and cloud diameter $20 \mathrm{~cm}$ ) are presented; also, dynamics of a single $2.4 \mathrm{~mm}$ steel particle is shown. The lines correspond to SOCRAT/VAPEX simulation while the experimental data are given by points. The accuracy obtained for a single particle is comparable with that of an analytical solution [12, 13], where the calculated curve is also located above the experimental points. As for the 
TABLE 2: Validation matrix of VAPEX-M module.

\begin{tabular}{lccc}
\hline Phenomena & FARO (JRC, Italy) & MAGICO (UCSB, US) & QUEOS (FZK, Germany) \\
\hline (1) Melt jet breakup & $\mathrm{X}$ & - & - \\
(2) Mixing of melt droplets with water & $\mathrm{X}$ & $\mathrm{X}$ & $\mathrm{X}$ \\
(3) Steam production & $\mathrm{X}$ & $\mathrm{X}$ & $\mathrm{X}$ \\
(4) Hydrogen generation & $\mathrm{X}$ & - & - \\
(5) Corium quenching & $\mathrm{X}$ & $\mathrm{O}$ & $\mathrm{O}$ \\
\hline
\end{tabular}

$\mathrm{X}$ : suitable for code validation.

O: partially suitable for code validation.

—: not occurring or not suitable.

concentrated particulate cloud (when "collective" effects are substantial), the best agreement between the calculations and experiments was achieved for the empirical coefficient in (7) $\chi=0.6$ (the curve in Figure 2 is drawn for this value). Also, in Figure 2, the results obtained by 2D code VAPEX$\mathrm{P}$ are shown by points [21]. Generally, good agreement can be observed, including the results of $2 \mathrm{D}$ simulations by VAPEX-P code as well as PM-ALPHA code results reported in $[12,13]$. It should be noted that better agreement of current $1 \mathrm{D}$ results was achieved by adjustment of parameter $\chi$ while 2D VAPEX-P results in [21] were obtained without any special adjustments.

In Figure 2, results obtained for a "hot" test Z1500/0$2[12,13]$ are presented $\left(\mathrm{ZrO}_{2}\right.$ particles, diameter $2.9 \mathrm{~mm}$, total mass $6.2 \mathrm{~kg}$, initial temperature $1300-1450^{\circ} \mathrm{C}$, volume fraction of particles $1.7 \%$, cloud length $158 \mathrm{~cm}$, cloud diameter $22.5 \mathrm{~cm}$, particle velocity $4.8 \mathrm{~m} / \mathrm{s}$, water depth $0.6 \mathrm{~m})$. The best agreement between the calculated results and experiments was obtained for the empirical parameter $\chi=0.45$ (see (7)), the curve plotted in Figure 2(a) was obtained with this value.

From the above results, as well as physical considerations $\left(\chi=0\right.$ for $\alpha_{d} \rightarrow 0$ and $\chi=1$ for densely packed particle clouds, $\alpha_{d} \geq 0.5$ ), a linear interpolation was assumed for the empirical parameter $\chi$ as a function of initial volume fraction of particles in the cloud

$\chi= \begin{cases}0.45\left(\frac{\alpha_{d}}{1 \cdot 10^{-2}}\right), & 0 \leq \alpha_{d} \leq 1 \cdot 10^{-2} \\ 0.45+0.15 \frac{\alpha_{d}-1 \cdot 10^{-2}}{9 \cdot 10^{-2}}, & 1 \cdot 10^{-2} \leq \alpha_{d} \leq 10 \cdot 10^{-2} \\ 0.6+0.4 \frac{\alpha_{d}-0.1}{0.4}, & 0.1 \leq \alpha_{d} \leq 0.5 \\ 1, & \alpha_{d} \geq 0.5\end{cases}$

This interpolation formula is implemented in VAPEX-M and used in all further calculations presented in the current paper. Of course, it can be improved provided that more extensive experimental data is available on sedimentation of dense particulate clouds.

In the experiment Z1500/0-2 [12, 13], the void fraction was determined at a single instant $t=0.35 \mathrm{~s}$ from the analysis of X-ray images. In Figure 2(b), this experimental point is plotted together with the calculated dependence of maximum void fraction in the pool. It can be seen that the calculated void fraction is about 30\% lower than measured, which, primarily, can be attributed to the use of 1D nodalization in SOKRAT; the experimental value was obtained in the central part of the cloud where boiling proceeds more intensively than at the periphery. In the 1D approximation, however, only cross-section-averaged flow parameters are calculated, so that the average volume fraction of vapour turns out to be lower.

Thus, calculations of MAGICO-2000 experiments [12, 13] show that SOKRAT/VAPEX code provides quite reasonable results in terms of sedimentation of cold and hot particulate clouds.

3.3. Calculation of QUEOS Experiments. In the QUEOS experiments $[14,15]$, more concentrated and hot particle clouds were used then in the MAGICO-2000 tests [12, 13]. An integral parameter of FCI process, that is, the vapour mass flowrate, was measured experimentally. For the validation purposes, two tests were chosen: Q10 $\left(\mathrm{ZrO}_{2}\right.$ particles of the diameter of $10 \mathrm{~mm}$, the total mass is $6.3 \mathrm{~kg}$, and the particle temperature is $1800 \mathrm{~K}$ ) and Q11 (Mo particles with the material density $\rho_{\text {Mo }}=10.5 \cdot 10^{3} \mathrm{~kg} / \mathrm{m}^{3}$, particle diameter $4.2 \mathrm{~mm}$, total mass is $5.7 \mathrm{~kg}$, temperature $1800 \mathrm{~K})$. Unfortunately, measurement uncertainties are not provided in $[14,15]$.

In the calculations, the average volume concentration of particles was set to $17 \%$ in accordance with the experimental conditions, the water depth was $2 \mathrm{~m}$, and the particle velocities on entry to the coolant were equal to $2 \mathrm{~m} / \mathrm{s}$. All dispersed material was supplied during the time interval equal to $0.075 \mathrm{~s}$.

The simulation results obtained by the VAPEX-M code are shown in Figure 2 for the experiments Q10 (a) and Q11 (b). The time dependencies of the vapour volume flowrates $q_{\mathrm{ev}}(t)$ and the total volume of vapour-generated $Q_{\mathrm{ev}}(t)=$ $\int_{0}^{t} q_{\mathrm{ev}}(t) d t$ are presented. Comparison of the calculated curves with the corresponding experimental data plotted in Figure 2 confirms the adequacy of the predictive capabilities of the VAPEX-M code with respect to the quantitative description of interaction of concentrated hot particle clouds with the liquid coolant. In particular, the duration of the active interaction phase, the increase rate of the volume flow, and total mass of vapour are well reproduced. The differences in the absolute values of the total volume of vapour visible in Figure 2(a) are most probably attributed to the shift between the calculated and experimental curves; in 
the experiments, at $t=0$ the volume of generated vapour is equal to $0.006 \mathrm{~m}^{3}$, and the vapour generation rate was about $0.06 \mathrm{~m}^{3} / \mathrm{s}$, whereas the calculations started with zero vapour production rate and, accordingly, zero volume of vapour. The reason for vapour generation before plunging of hot particles in the experiments is not clear, which does not allow the same initial conditions to be specified in the calculation. However, it is reasonable to expect that this initial vapour production and the vapour accumulation by $t=0$ were caused by bringing water to saturation before plunging the particles. Alternatively, this could be attributed to gradual start of particle plunging while in the calculations all particles were released instantaneously. In any case, the effect is limited to the initial stage only; it will be dominated by the intensive vapour release during the active phase of fuel-coolant interaction. To account for the initial amount of vapour, in Figure 2(a), the calculated curve $Q_{\mathrm{ev}}(t)$ shifted in the vertical direction by the value of $0.006 \mathrm{~m}^{3}$ (curve 3) is also presented. One can see that the calculated data agree quite well with the experimental measurements. The nonmonotonous behaviour of vapour release rate observed in Q11 experiment at later times (after $0.3 \mathrm{~s}$ ) is not reproduced in the calculations; the reasons for this discrepancy are not clear (it does not seem to have occurred in Q10 experiment).

Generally, one can see that SOCRAT/VAPEX calculations give adequate quantitative description of interaction of concentrated hot particle clouds with the liquid coolant, in particular, the duration of the active interaction phase, the transient volumetric flowrate, and total volume of vapour. The SOCRAT/VAPEX-M results were also compared with the earlier 2D simulations carried out by the standalone VAPEX-P code [21]. The accuracy of the numerical predictions obtained by the two codes turned out to be comparable, which also confirms the adequacy of the onedimensional model in the application to FCI problems.

3.4. Calculation of FARO Experiments. In the FARO experiments [16-18], fuel-coolant interaction was studied using up to $200 \mathrm{~kg}$ of $\mathrm{UO}_{2}-\mathrm{ZrO}_{2}(-\mathrm{Zr})$ melt ( $80 / 20 \%$ by mass) at the temperature of up to $3200 \mathrm{~K}$. Validation of SOCRAT/VAPEX$\mathrm{M}$ code was carried out by modelling three experiments of the series performed in the saturated conditions, namely, FARO L-14, FARO L-24, and FARO L-28. The experimental parameters are summarized in Table 3 [16-18].

The computational domain consisted of three interconnected volumes with the cross-section area of $0.396 \mathrm{~m}^{2}$, of which the lower one was filled with water (its height was equal to the water level in the corresponding experiment), the middle and upper volumes were filled with the mixture of steam and argon in the proportions (by mass) 7723\% (FARO L-14) and 98-2\% (FARO L-24 and L-28). The height of the middle volume corresponded to the free fall height in Table 3; the upper volume height was chosen to provide necessary gas space volume. The nodalization scheme included 80 computational cells in the lower volume, 40 cells in the middle volume (detailed nodalization is necessary here because water level is rising due to the

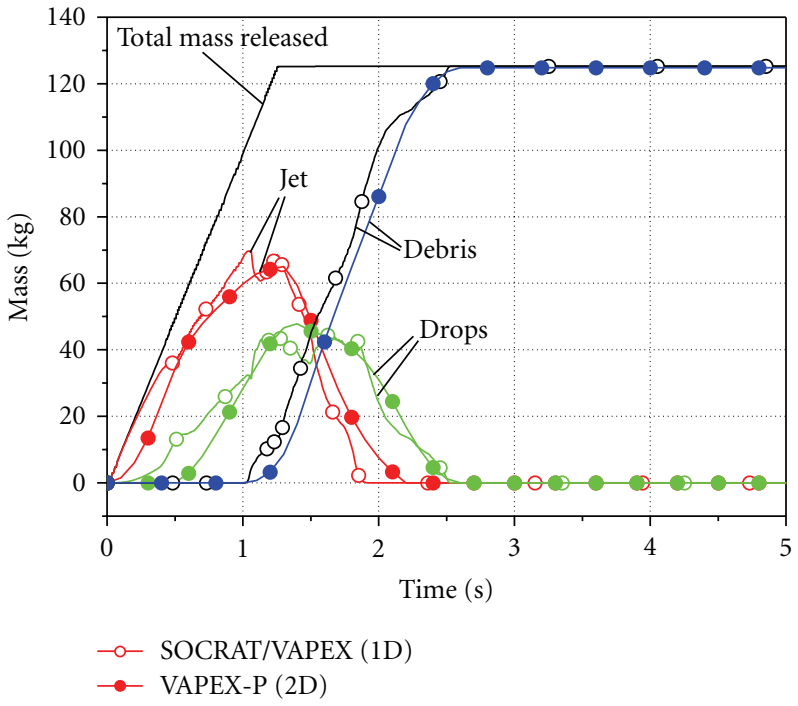

FIGURE 4: Melt fragmentation and fallout in FARO L-14 experiment (calculated).

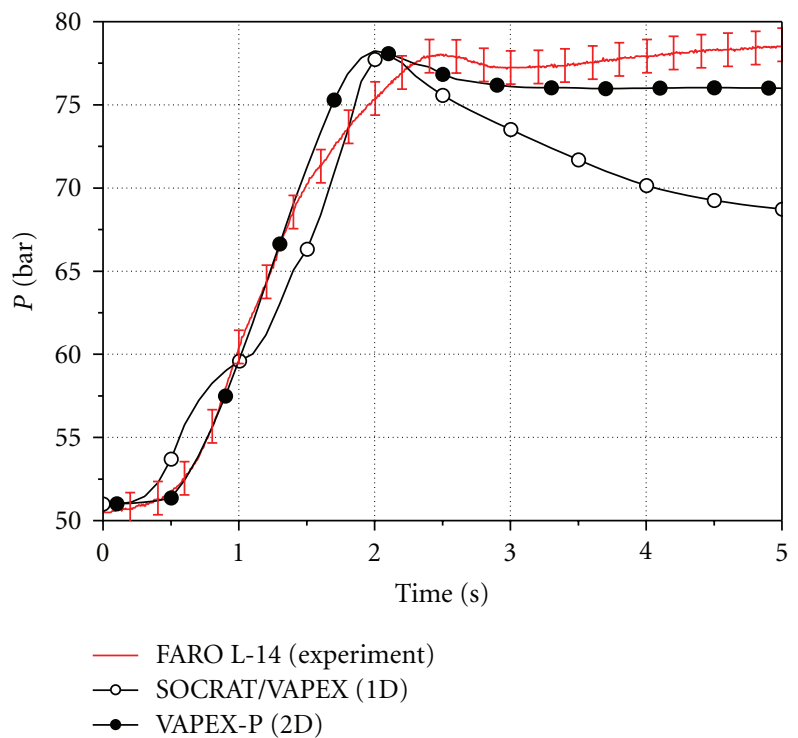

Figure 5: Pressure history in FARO L-14 experiment.

swelling of two-phase mixture), while the upper volume in which the flow is single-phase contained 10 cells. In the fragmentation model (see (13)), the initial diameter of the particles representing the melt jet was taken equal to the jet diameter. For the fragmented droplets, the diameter was taken equal to the experimental value for the debris diameters given in Table 1, and the secondary fragmentation was not taken into account.

In the preliminary calculations of each experiment carried out by SOCRAT/VAPEX code, it turned out that to obtain correct pressure rise curves, it was necessary to set the number of leading particles which are subject to fragmentation to $N_{L}=25$ (see (13) and discussion of fragmentation model thereafter), which is much higher a 
TABLE 3: FARO experimental conditions.

\begin{tabular}{|c|c|c|c|}
\hline \multirow{2}{*}{ Parameter } & \multicolumn{3}{|c|}{ Experiment } \\
\hline & FARO L-14 & FARO L-24 & FARO L-28 \\
\hline Test section & TERMOS & TERMOS & FAT \\
\hline Water level, m & 2.05 & 2.02 & 1.44 \\
\hline Water mass, kg & 623 & 517 & 517 \\
\hline Volume of gas space, $\mathrm{m}^{3}$ & 1.26 & 1.29 & 3.5 \\
\hline Temperature & $263 \mathrm{C} / 536 \mathrm{~K}$ & $151 \mathrm{C} / 424 \mathrm{~K}$ & $151 \mathrm{C} / 424 \mathrm{~K}$ \\
\hline Pressure, $\mathrm{MPa}$ & 5.1 & 0.51 & 0.51 \\
\hline Melt mass, $\mathrm{kg}$ & 125 & 177 & 174.9 \\
\hline Melt temperature, $\mathrm{K}$ & 3073 & 3052 & 3052 \\
\hline Diameter of melt jet, $\mathrm{m}$ & 0.094 & 0.094 & 0.044 \\
\hline Free fall height, $\mathrm{m}$ & 1.04 & 1.065 & 0.9 \\
\hline Debris mean diameter, $\mathrm{mm}$ & 4.8 & 2.6 & 3.5 \\
\hline
\end{tabular}

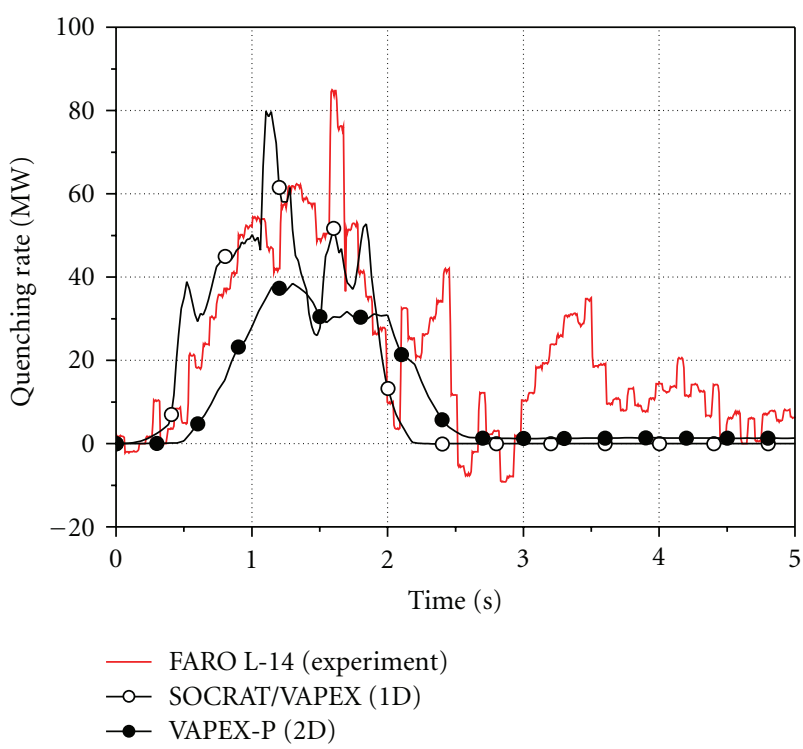

FIgURE 6: Quenching rate in FARO L-14 experiment.

number than 1 or two leading particles implied in the original fragmentation model [20]. Note also that, hydrogen release was found to be noticeable in FARO experiments. To simulate this, an appropriate (i.e., giving the experimentally observed total hydrogen release) amount of nonoxidized zirconium was added to the melt in the calculations (however, the heat release due to its oxidation was not taken into account). Below, the results obtained are presented and compared with the experimental data as well as with the results of earlier 2D calculations by VAPEX-P code [21] for FARO L-14 and FARO L-24 experiments. For FARO L-28 case, new 2D calculations were carried out by 2D VAPEX$\mathrm{P}$ code, on order to make comparisons with experiments and SOCRAT/VAPEX 1D code possible.

In Figures $4,5,6,7,8,9,10,11$, and 12 , the results calculated for the FARO experiments are presented. For the processes of jet fragmentation and sedimentation of melt droplets onto the bottom plate (debris formation), only

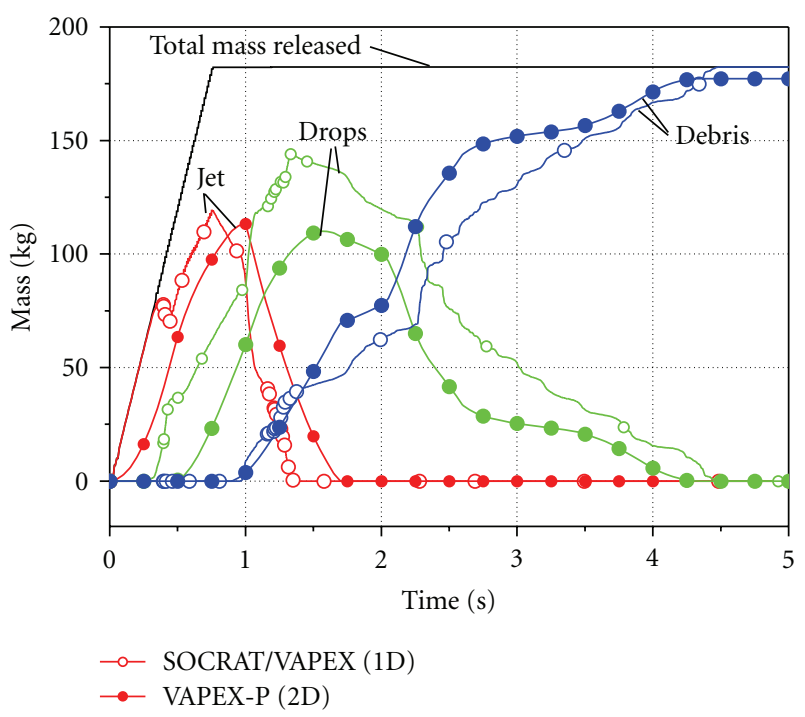

Figure 7: Melt fragmentation and fallout in FARO L-24 experiment (calculated).

computational results are presented, since these quantities were not measured in the experiments. The accuracy of pressure measurements in Figures 5, 8, and 11, equal to \pm 1 bar, is indicated by the error bars. No information on the accuracy of quenching rate determination is available in [1618]. Additionally, the water temperature histories at the level of $80 \mathrm{~cm}$ above the vessel bottom were compared with the measurements at a distance of $150 \mathrm{~mm}$ from the axis. Finally, in Figures 6, 9, and 12, the quenching rates characterizing the energy transfer in the FCI process are shown.

From the analysis of calculated and experimental curves shown in Figures 4, 5, 6, 7, 8, 9, 10, 11, and 12, we can conclude that SOCRAT/VAPEX code adequately reproduces the main features of FCI. In particular, realistic pressure rise dynamics, quenching rate, and duration of the active phase of FCI are obtained in the calculations. The main difference is observed in the pressure histories (Figures 5, 8, and 11) while the experimental curves reach nearly a constant level 


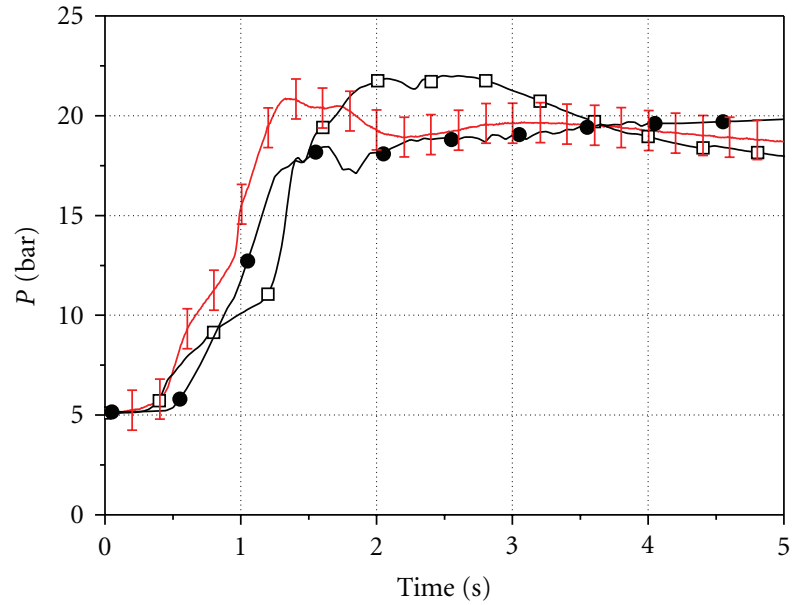

- FARO L-24 (experiment)

$\rightarrow$ SOCRAT/VAPEX (1D)

$\rightarrow$ VAPEX-P (2D)

Figure 8: Pressure history in FARO L-24 experiment.

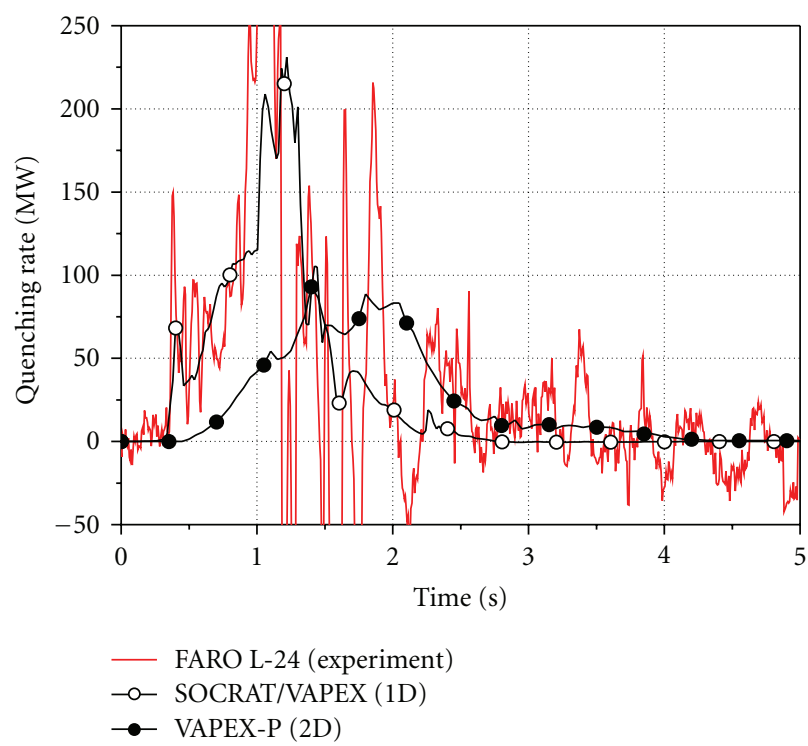

FIgURE 9: Quenching rate in FARO L-24 experiment.

(and even grow slightly) after the end of the active phase, the calculated pressures gradually decrease. The main reason for this is that energy transfer between the debris and the coolant (see the spikes on the experimental quenching rate curves in Figures 6, 9, and 12 after complete settling of the dispersed particles) is not included in the SOCRAT/VAPEX model.

Another possible reason is related to the separation of liquid and vapour phases; in reality, much of the vapor generated due to FCI rises into the upper gas space, and the liquid and vapor phases are separated and interact along the water level interface only. In the one-dimensional thermohydraulic approach taken in SOKRAT/VAPEX, such phase separation cannot be described adequately; the interaction between the hotter vapour and colder liquid after the total

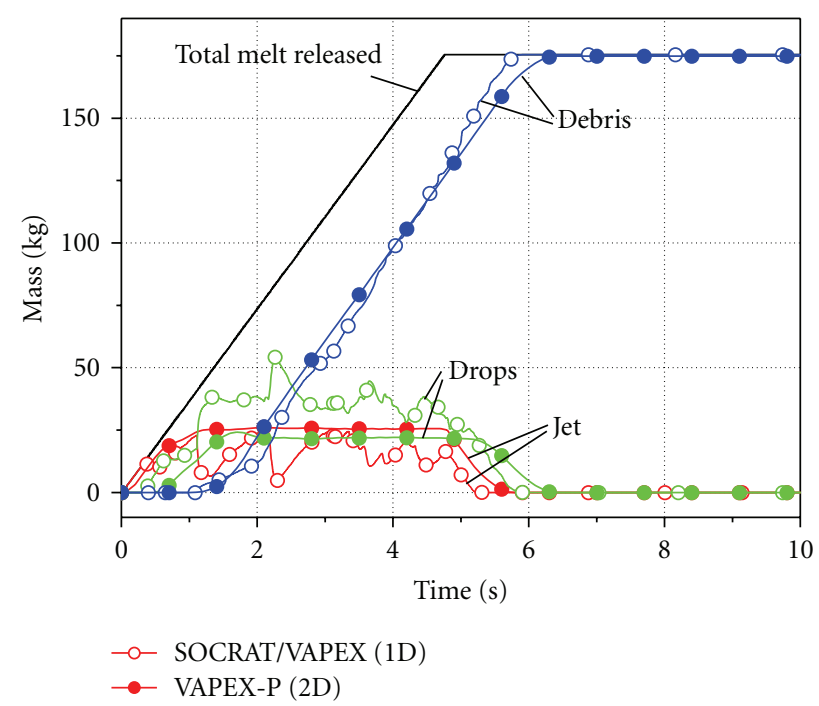

Figure 10: Melt fragmentation and fallout in FARO L-28 experiment (calculated).

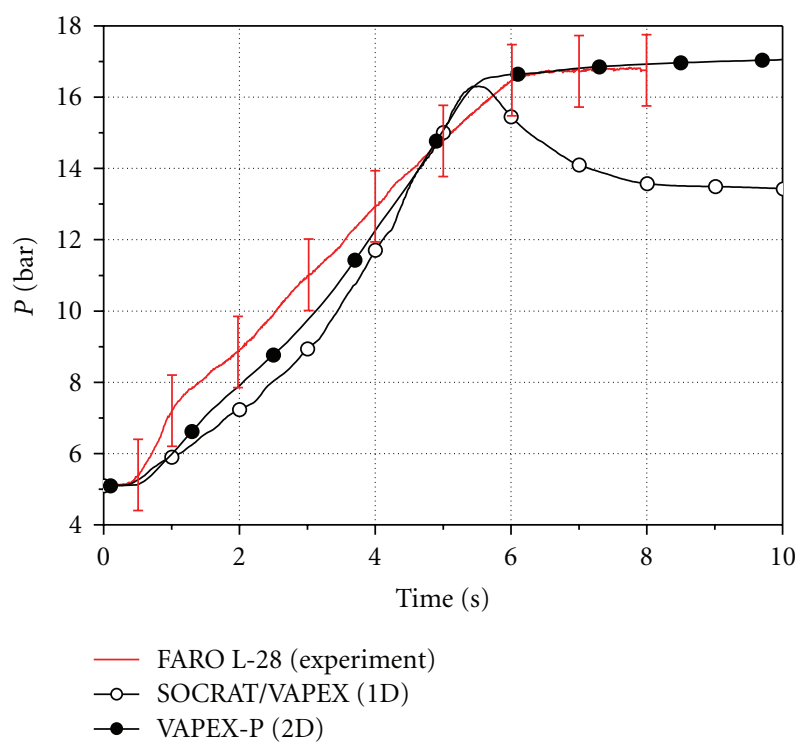

FIgURE 11: Pressure history in FARO L-28 experiment.

melt sedimentation is overestimated, leading to more rapid vapour condensation and pressure decrease. This is also confirmed by the comparison of $1 \mathrm{D}$ simulations with the $2 \mathrm{D}$ results which exhibit the pressure levelling after the end of active phase of FCI.

Also note that for the experiment FARO L-28 (see Figure 11) both the one-dimensional and two-dimensional simulations give the pressure rise curve which starts at a lower slope than was observed in the experiment, and then gradually the pressure increase rate becomes higher than the experimental one. In contrast, the experimental curve shows steady pressure increase which also correlates with the steady quenching rate observed in Figure 12. The reasons for this discrepancy are not clear at the moment and deserve 


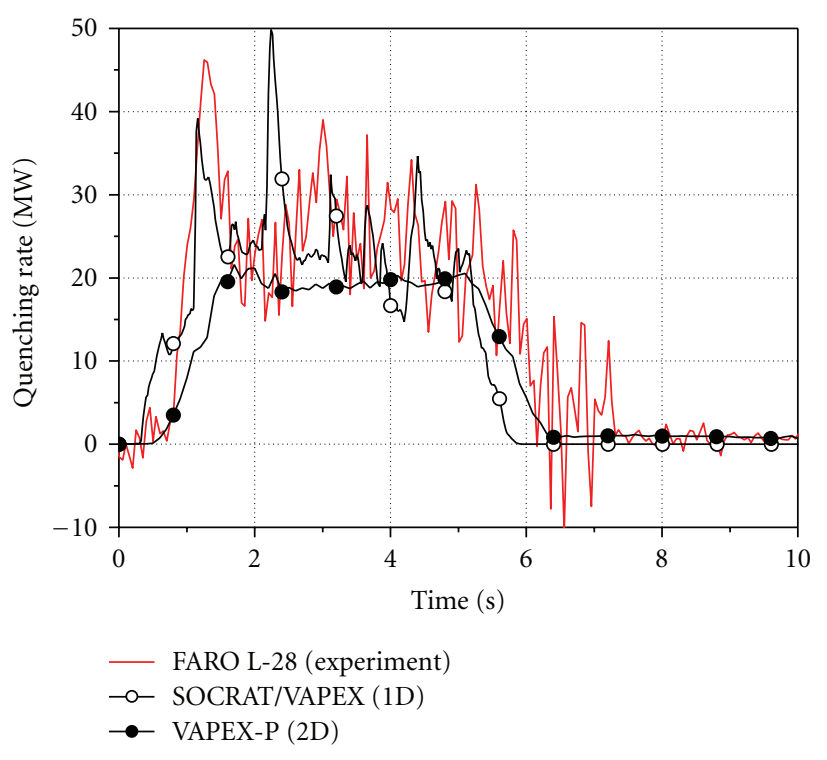

Figure 12: Quenching rate in FARO L-28 experiment.

more detailed study, given that the discrepancy is observed in two codes which rely on different correlations for melt jet fragmentation.

Another difference quite noticeable in Figure 9 is a sharp spike of quenching rate observed in the FARO L-24 test at $t=1 \mathrm{~s}$ when the peak quenching rate reached some $700 \mathrm{MW}$. Also, pronounced oscillations are observed on the quenching rate graph. These can be attributed to the development of instability which enhanced the quenching rate.

It is interesting to note that, generally speaking, the agreement with the experimental data of the one-dimensional results presented in Figures 4-12 is not worse (and, in some cases, even better) than of the data calculated by twodimensional model. For example, the quenching rates in Figures 6 and 9 are better reproduced in the one-dimensional calculation, probably because the lateral heat transfer by such mechanisms as radiation and turbulent mixing, which was not included in the thermohydraulic multifluid model, is somehow imitated by the averaging over the horizontal dimension in 1D model. These questions are worth of special study, however.

\section{Conclusions}

The results of numerical simulations confirmed the adequacy of the mathematical models for fuel-coolant interaction used in the SOKRAT/VAPEX code and their numerical implementation. It is shown that the model reproduces with practically acceptable accuracy the main features of interaction between the dispersed and liquid phases, including sedimentation of single particles, particulate clouds, and corium melts subjected to fragmentation. This enables the combined code SOKRAT/VAPEX to be used in the studies of severe accidents at nuclear power plants with LWR reactors.

\section{Acknowledgments}

This research was supported in the frame of the Russian Federal Target Program "Scientific and scientific-pedagogical personnel of innovative Russia" in 2009-2013 by the State Contract no. $\Pi 182$ of 16.07.2009, the State Contract no. 14.740.11.0093 of 08.09.2010, and by Russian Foundation for Basic Research (Projects nos. 09-08-00959a and 09-0800968a).

\section{References}

[1] L. C. Witte and J. E. Cox, "Thermal explosion hazards," Advances in Nuclear Science and Technology, vol. 7, pp. 329364, 1973.

[2] A. W. Cronenberg and R. Benz, "Vapor explosion phenomena with respect to nuclear reactor safety assessment," Advances in Nuclear Science and Technology, vol. 12, pp. 247-334, 1980.

[3] D. F. Fletcher and R. P. Anderson, "A review of pressureinduced propagation models of the vapour explosion process," Progress in Nuclear Energy, vol. 23, no. 2, pp. 137-179, 1990.

[4] G. Berthoud, "Vapor explosions," Annual Review of Fluid Mechanics, vol. 32, pp. 573-611, 2000.

[5] R. Meignen, D. Magallon, K.-H. Bang et al., "Comparative review of FCI computer models used in the OECD-SERENA program," in Proceedings of the American Nuclear SocietyInternational Congress on Advances in Nuclear Power Plants (ICAPP '05), vol. 1, pp. 411-423, 2005.

[6] V. I. Melikhov, O. I. Melikhov, Y. V. Parfenov, and A. V. Sokolin, "Analysis of FARO fuel-coolant interaction experiment by the VAPEX code," Atomic Energy, vol. 92, no. 2, pp. 91-95, 2001 (Russian).

[7] M. V. Davydov, V. I. Melikhov, O. I. Melikhov, and Y. V. Parfenov, "Analysis of MAGICO and QUEOS premixing experiments (vapour explosions in severe accidents) by the VAPEX code," Communications of High Schools. Nuclear Power Engineeringy, no. 3, pp. 72-79, 2001 (Russian).

[8] V. I. Melikhov, O. I. Melikhov, and Y. V. Parfenov, "Numerical modelling of melt jet-water premixing by the VAPEX-P code," Thermoengineering, no. 11, pp. 35-39, 2003 (Russian).

[9] V. I. Melikhov, O. I. Melikhov, and S. E. Yakush, "Analysis of large scale fuel-coolant interaction experiments by VAPEX code," High Temperature, vol. 45, no. 4, pp. 565-574, 2007 (Russian).

[10] V. V. Bezlepkin, V. G. Sidorov, A. V. Lukin et al., "Development of computer codes for modelling of severe accidents at NPPs," Thermoengineering, no. 2, pp. 5-11, 2004 (Russian).

[11] M. S. Veshchunov, A. E. Kiselev, and V. F. Strizhov, "Development of SVECHA code for the modelling of in-vessel phase of severe accident at Pressurized Water Reactors," Izvestiya, no. 2, pp. 6-21, 2004 (Russian).

[12] S. Angelini, W. W. Yuen, and T. G. Theofanous, "Premixingrelated behavior of steam explosions," Nuclear Engineering and Design, vol. 155, no. 1-2, pp. 115-157, 1995.

[13] S. Angelini, W. W. Yuen, and T. G. Theofanous, "The mixing of particle clouds plunging into water," in Proceedings of the NURETH-7, vol. 3, pp. 1754-1778, Saratoga Springs, NY, USA, September 1995.

[14] L. Meyer and G. Schumacher, "QUEOS, a simulationexperiment of the premixing phase of a steam explosion with hot spheres in water," FZKA Report 5612, Forschungszentrum, Karlsruhe, Germany, 1996. 
[15] H. Jacobs, E. V. Berg, G. Berthoud et al., "Studies of principal processes during melt-water premixing," in FISA95-EU Research on Severe Accidents, G. Van Goethem, W. Balz, and E. Della Loggia, Eds., pp. 165-183, Brussels, Belgium, 1996.

[16] A. Annunziato, A. Yerkess, and C. Addabbo, "FARO and KROTOS code simulation and analysis at JRC Ispra," Nuclear Engineering and Design, vol. 189, no. 1, pp. 359-378, 1999.

[17] D. Magallon, I. Huhtiniemi, and H. Hohmann, "Lessons learnt from FARO/TERMOS corium melt quenching experiments," Nuclear Engineering and Design, vol. 189, no. 1, pp. 223-238, 1999.

[18] D. Magallon and I. Huhtiniemi, "Corium melt quenching tests at low pressure and subcooled water in FARO," Nuclear Engineering and Design, vol. 204, no. 1-3, pp. 369-376, 2001.

[19] N. I. Kolev, Multiphase Flow Dynamics, Springer, Berlin, Germany, 2005.

[20] C. C. Chu and M. L. Corradini, "One-dimensional transient fluid model for fuel/coolant interaction analysis," Nuclear Science and Engineering, vol. 101, no. 1, pp. 48-71, 1989.

[21] M. V. Davydov, V. I. Melikhov, O. I. Melikhov, and Y. V. Parfenov, "Analysis of MAGICO and QUEOS experiments on premixing of particle clouds in water (steam explosions in severe accidents) by VAPEX code," Nuclear Energy, no. 3, pp. 72-79, 2001. 

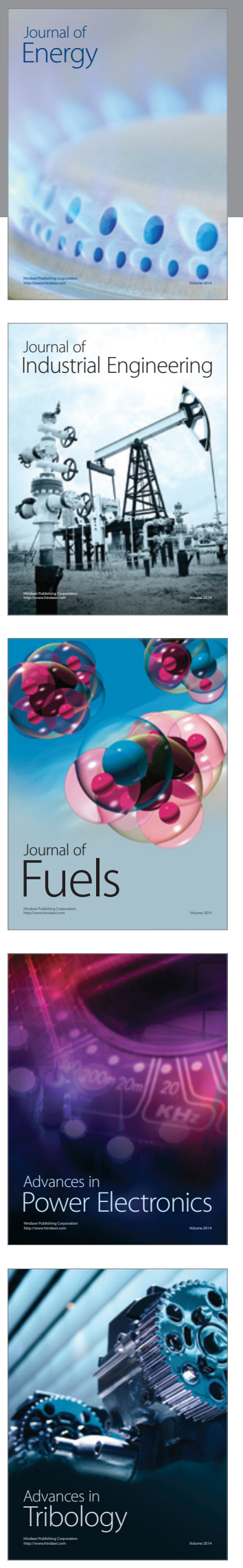
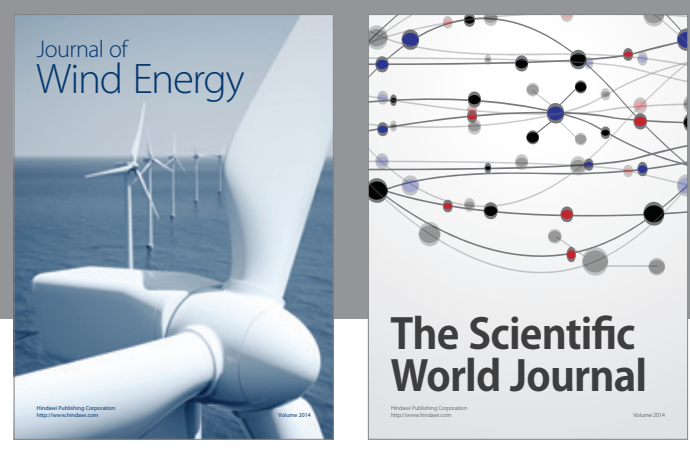

The Scientific World Journal

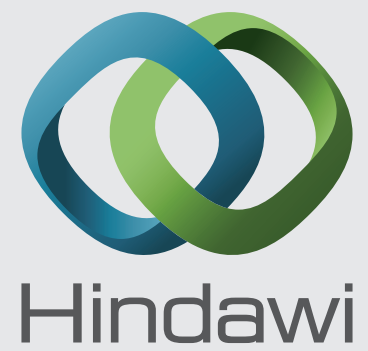

Submit your manuscripts at http://www.hindawi.com
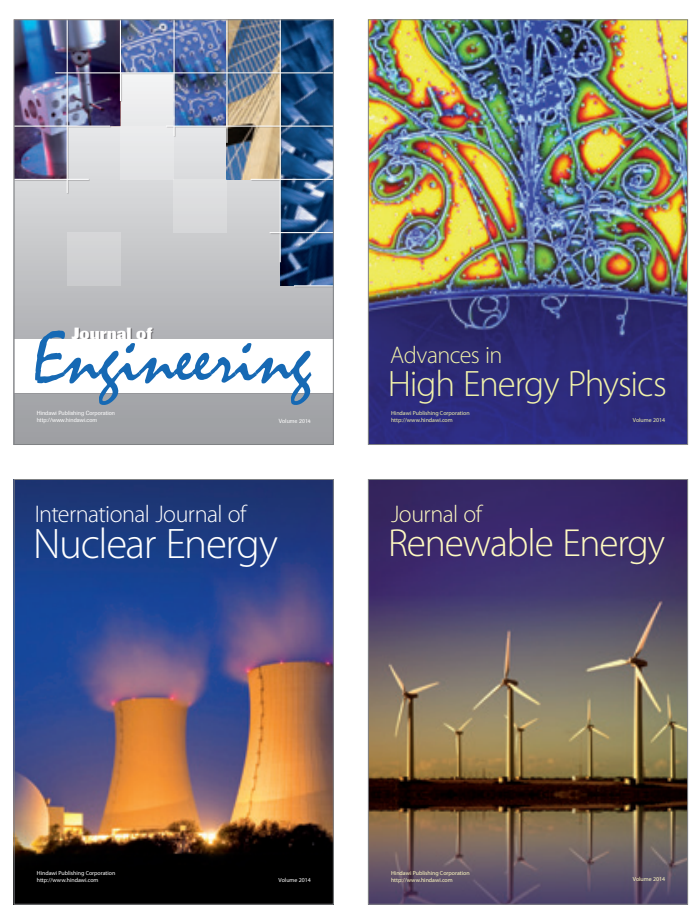

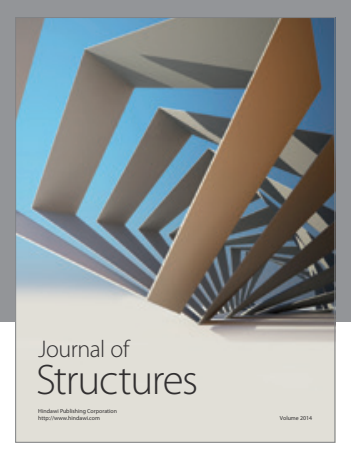

Rotating
Mechinery
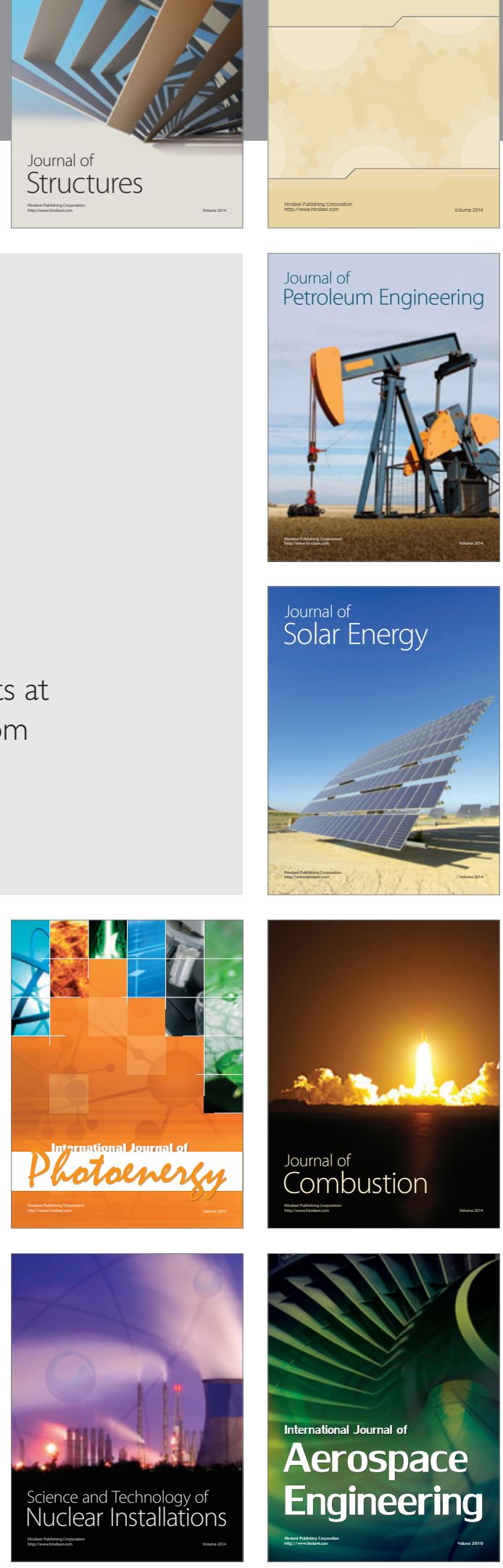